\title{
Are teamwork and professional autonomy compatible, and do they result in improved hospital care?
}

\author{
A M Rafferty, J Ball, L H Aiken
}

\begin{abstract}
A postal questionnaire survey of 10022 staff nurses in 32 hospitals in England was undertaken to explore the relationship between interdisciplinary teamwork and nurse autonomy on patient and nurse outcomes and nurse assessed quality of care. The key variables of nursing autonomy, control over resources, relationship with doctors, emotional exhaustion, and decision making were found to correlate with one another as well as having a relationship with nurse assessed quality of care and nurse satisfaction. Nursing autonomy was positively correlated with better perceptions of the quality of care delivered and higher levels of job satisfaction. Analysis of team working by job characteristics showed a small but significant difference in the level of teamwork between full time and part time nurses. No significant differences were found by type of contract (permanent $v$ short term), speciality of ward/unit, shift length, or job title. Nurses with higher teamwork scores were significantly more likely to be satisfied with their jobs, planned to stay in them, and had lower burnout scores. Higher teamwork scores were associated with higher levels of nurse assessed quality of care, perceived quality improvement over the last year, and confidence that patients could manage their care when discharged. Nurses with higher teamwork scores also exhibited higher levels of autonomy and were more involved in decision making. A strong association was found between teamwork and autonomy; this interaction suggests synergy rather than conflict. Organisations should therefore be encouraged to promote nurse autonomy without fearing that it might undermine teamwork.
\end{abstract}

(Quality in Health Care 2001;10(Suppl II):ii32-ii37)

Keywords: teamwork; nursing autonomy; interprofessional working; quality of care

Center for Health Outcomes and Policy Research, University of Pennsylvania, Philadelphia, PA 19046-6096, USA L H Aiken, Claire $M$ Fagin professor of nursing $\mathcal{E}$ director

Correspondence to: Dr A M Rafferty anne-marie.rafferty@, lshtm.ac.uk

The complexity of health care has increased enormously over the past two decades as a result of biomedical advances, the medicalisation of everyday problems, the ageing of the population, and regulatory and cost containment activities. The responsibilities of doctors, nurses, and other health professionals have increased accordingly, the boundaries between professions have blurred, and the need for interdependence among professionals and other support and managerial personnel has increased. ${ }^{1}$ At the same time, however, health professionals perceive an erosion in their autonomy which undermines their satisfaction with their work and contributes to job turnover and an unstable dissatisfied workforce. Over the past decade managers have increasingly turned to efficiency models for restructuring healthcare settings, drawing from manufacturing examples which emphasise teamwork over professional autonomy. Many of these ventures have failed to produce more efficient or effective care and, in the process, have given teamwork a bad name, ${ }^{2}$ especially among nurses who perceive a direct relationship between managerial mandates of reengineering involving teams and their deteriorating working conditions. ${ }^{3}$

Yet when there is a mistake made in health care with disastrous consequences, the failure of interdisciplinary communication is often to blame. The recently published Kennedy Inquiry into the death of babies undergoing heart surgery at the Bristol Royal Infirmary reminds us all too tragically of the importance of teamwork and the costs of its limited performance and effectiveness (http://www.bristolinquiry.org.uk.report). Significantly, the surgeons considered themselves as having very effective teamwork, but these were their "teams" which they led rather than being a part of them. Similarly, "teams" were configured as those of like professionals rather than multiprofessional and were profoundly hierarchical. The tensions between doctors and nurses and the barriers to interprofessional teamwork have generated considerable comment. ${ }^{4-6}$ Essentially, the inequalities in the division of labour are attributed to inequalities in power relations with doctors positioned at the peak of the pyramid. ${ }^{7}$ There is a long history of interprofessional conflict between doctors and nurses ranging from the early disputes over boundaries of authority and jurisdiction. ${ }^{8}$ Gender antagonism has often been identified as being at the root of this. A catalogue of conflicts
Key messages

- Higher reported levels of teamwork impact on nurse assessed quality of care.

- A strong association was found between teamwork and autonomy.

- This interaction suggests synergy rather than conflict.

- Organisations may promote nurse autonomy and enhance teamwork. 
emerged from the empirical study by Walby et $a l^{9}$ of medicine and nursing work in which over 400 disputes were identified. Relations with managers have also been seen as problematic and characterised as oppositional in nature..$^{10}$ Healthcare work is complex and subject to many cross-cutting pressures. The very nature of its division of labour-its intricate intersection of structural power relations-means that it is almost inevitably a site for contest and negotiation.

Professional work involves dependent, interdependent, and independent elements. ${ }^{12} \mathrm{Ab}-$ bott ${ }^{13}$ recognised this matrix of relations in his "system" of professions in which each profession is aligned to a set of tasks by jurisdictional ties. These claims can be made in public, legal, and work place contexts. Within the work place, formalised job descriptions map only loosely onto job content, the division of labour being the product of custom and a negotiated order. ${ }^{14}$ Much of the burden of negotiation is carried by professionals themselves "translating" formal and public professional mandates into local and specific practices.

\section{Evaluating teamwork}

While the value of teamwork has an intuitive appeal, its impact on organisational processes and outcomes is more difficult to measure. Among the benefits claimed for teamwork are: improved financial outcomes, reduced staff turnover and absenteeism, higher quality of care, increased staff motivation, reduced conflict, and better patient outcomes. ${ }^{15}{ }^{16}$ The potential benefits of teamwork have been attributed to the positive impact upon the psychological health and well being of members. ${ }^{17}$ Lower levels of stress and greater effectiveness and innovation in primary care and community mental health are associated with quality of teamwork. ${ }^{18}$

Within secondary care, ICUs have provided a rich research environment for studying teams. Shortell et $a l^{19}$ in the USA have investigated a number of performance indicators and tested a number of hypotheses including the level of available technology, case mix, nurse staffing and patient ratios, and caregiver interaction. Caregiver interaction was a combined measure of five dimensions: culture (shared norms, beliefs and expectations), leadership, coordination (within and between ICUs and other acute units), communication, and conflict management. Communication was identified as being of particular interest because of the complex sociotechnical dynamics of the ICU environment. In particular, caregiver interaction was associated negatively with nursing turnover, case mix adjusted length of stay and "evaluated quality of care", and "evaluated ability to meet family needs". Research by Zimmerman et a ${ }^{20}$ claimed that a greater sense of collegiality, strong nursing, and medical leadership with patient-centred culture produced "superior organisational practices". Research into interventions designed to promote collaboration between nurses and doctors suggests that moderate gains in healthcare processes rather than outcomes are possible. ${ }^{21}$ Zwarenstein and Bryant ${ }^{22}$ in a Cochrane review of the research identified only two randomised controlled trials which demonstrated a modest impact of enhanced nursephysician collaboration on length of stay and hospital costs and no discernible difference on mortality.

\section{The International Hospital Outcomes Study}

A number of studies point to the positive benefits of interprofessional collaboration. In trying to unravel the operant mechanisms in better hospital outcomes we have surveyed a large number of variables - many of them organisational in nature-in a major international study of hospital outcomes. ${ }^{23}$ The International Hospital Outcomes Study derives from one aspect of hospital workforce organisation which is gaining increased research based attention-the "magnet" hospital. The notion of these US magnet hospitals has been recognised to be of potential relevance in other countries including the UK. ${ }^{24}$ Magnet hospitals were first identified in the early 1980 s as institutions with better than average measures of nursing staff job satisfaction, relations with physicians, and autonomy. Recent research has also suggested they may have better than average care outcomes. The most detailed study of the possible link between mortality rates and magnet hospitals was conducted by Aiken et $a l^{25}$ in which the mortality rates in 39 magnet hospitals and 195 control hospitals were analysed using multivariate matched sampling to control for hospital characteristics. Magnet hospitals were found to have a $4.6 \%$ lower mortality rate for Medicare patients than the control hospitals, and a follow up study by Aiken $e t a^{26}$ found that magnet hospitals had significantly lower AIDS mortality than matched hospitals. The mortality advantage of magnet hospitals was shown to be related to better nurse staffing and an organisational climate supportive of professional nursing practice. Magnet hospitals were characterised by nurses having greater autonomy, more control over the clinical care setting, and better relations with physicians compared with matched control hospitals. Further research work on the relationship between the organisation of nursing care, mortality rates, and complications is now underway in the USA and other countries. ${ }^{23}$

Although magnet hospitals have been of interest in the US for 15 years, the research base on their effectiveness is relatively limited, partly because different studies have adopted different methodologies and partly because the sample population of hospitals has changed since magnet hospitals were first identified in the early 1980s, both in terms of magnitude and organisational characteristics. More recent research represents a more robust methodological approach.

To this end, an international hospital outcomes study consortium comprising seven interdisciplinary research teams in the UK, Canada, Germany, and the US has been established with an emphasis on the "manipulable" 
aspects of hospital care and the manner in which hospital organisation, policies, and resources affect patient outcomes. ${ }^{27}$ The consortium is a research coalition led by the Center for Health Outcomes and Policy Research at the University of Pennsylvania and includes the University of Toronto, Institute for Clinical Evaluative Sciences, and Mount Sinai Hospital, Toronto; University of Alberta; University of British Columbia; London School of Hygiene and Tropical Medicine and CASPE Research, Inc, England; Glasgow Caledonian University and the Nursing Research Initiative of Scotland; and the Agnes Karll Institute for Nursing Research and Hannover Medical School, Germany.

While a number of worrying trends have emerged from intercountry analysis of nurses' job satisfaction, intention to leave, and high levels of burnout, not all aspects of work were regarded as unsatisfactory. Indeed, $75 \%$ of nurses across all countries reported that they work with physicians who provide high quality care and $85 \%$ said they work with nurses who are clinically competent. ${ }^{28}$ Moreover, nursedoctor relations overall seem to be in good order. Following research in the USA which showed that magnet hospitals that had superior outcomes had both good relations between doctors and nurses and high nurse autonomy, we investigated the relationship between interprofessional teamwork and nurse autonomy in UK hospitals and the implications for patient and nurse outcomes such as nurse assessed quality of care.

\section{The survey in the UK}

As part of the International Hospital Outcomes Study we surveyed nurses in 32 hospitals in England between 1998 and 1999. Details of the methodological approach adopted for the study are given elsewhere. ${ }^{29}$ The hospital sample was drawn from four of the eight regions of England and only those hospitals known to have patient outcome data of a good standard (managed by an external agency) were selected. In total, 10022 staff nurses (grades D, $\mathrm{E}$ or $\mathrm{F}$ on the Whitley pay scale or equivalent) working in surgical or medical settings were surveyed; 5006 usable responses were returned giving a response rate of $50 \%$. The 12 page questionnaire used was a modified version of the standard questionnaire used by the research groups participating in the international study.

Core constituents were integrated into a single questionnaire design. These included:

- details of current job (including grade, speciality, working hours);
- an adapted version of the Nursing Workload Index (NWI);

- Maslach Burnout Inventory ${ }^{30}$;

- job characteristics (satisfaction, role change, sickness absence, and needle stick injury);

- patient and nurse staffing numbers for the last shift they worked;

- background of respondents (age, sex, ethnicity, and qualifications).

An additional section on decision making was included as part of the UK questionnaire. Respondents were asked to rate on a 4 point scale (from "not at all" to "a lot") the extent to which they were involved in 21 patient care and work related decisions. This was included so that decision making behaviour could be gauged in addition to nurses' perceptions of their nursing autonomy.

The research sought to characterise the working practice environment in terms of the following five key dimensions:

- nursing autonomy

- control over resources

- relationship with doctors

- emotional exhaustion

- decision making

The first three dimensions were measured by subscales of the NWI. ${ }^{31}$ Emotional exhaustion is a subscale of the Maslach Burnout Inventory, a measure that has been widely used in studies of a number of different occupations. The scores in the decision making section included in the UK surveys were summed to create a single scale indicating involvement in decisions.

ANALYSIS OF DATA

The analysis first explored the nature of the relationship between the five key variables and revealed that they were correlated with one another (table 1) and with nurse assessed quality of care and nurse satisfaction. Not only were there significant relationships between the scales, but in regression analysis the scores for the other scales could be used to predict the autonomy scale scores. Further analysis revealed that the nursing autonomy scale was positively correlated with better perceptions of the quality of care delivered and higher levels of job satisfaction.

The nursing autonomy scale appeared to play a pivotal role in defining the clinical environment and US research had revealed it to be greater in magnet hospitals. But what exactly does the nursing autonomy scale refer to and how does the construct of professional autonomy of one group relate to the principles of team working? Intuitively it seemed that team working and autonomy could be viewed as

Table 1 Correlations between scales, job satisfaction, and quality of care

\begin{tabular}{llllllll}
\hline & Autonomy & $\begin{array}{l}\text { Control over } \\
\text { resources }\end{array}$ & $\begin{array}{l}\text { Relationship } \\
\text { with doctors }\end{array}$ & Burnout & $\begin{array}{l}\text { Decision } \\
\text { making }\end{array}$ & $\begin{array}{l}\text { fob } \\
\text { satisfaction }\end{array}$ & $\begin{array}{l}\text { Perceived } \\
\text { quality of care }\end{array}$ \\
\hline Autonomy & - & & & & & & \\
Control & 0.645 & - & & & & \\
Relationship with doctors & 0.376 & 0.348 & - & & & \\
Burnout & -0.378 & -0.455 & -0.219 & - & -0.094 & - & - \\
Decision making & 0.336 & 0.212 & 1.25 & -0.504 & 0.159 & - \\
Job satisfaction & 0.415 & 0.437 & 0.238 & -0.334 & 0.171 & 0.371 & - \\
Perceived quality of care & 0.395 & 0.531 & 0.255 & - & & \\
\hline
\end{tabular}

All correlations are significant ( $\mathrm{p}<0.001$; two tailed). 
Table 2 Mean (SD) scores of teamwork items from the Nursing Workload Index $(n=4681)$

\begin{tabular}{|c|c|c|c|c|}
\hline & & & Mean & $S D$ \\
\hline \multicolumn{3}{|c|}{ Doctors and nurses have good working relationships } & 3.04 & 0.62 \\
\hline \multicolumn{3}{|c|}{ Ward management that is supportive of nurses } & 2.81 & 0.92 \\
\hline \multicolumn{3}{|c|}{ Ward manager/sister who is a good manager and } & 2.85 & 0.98 \\
\hline \multicolumn{3}{|c|}{$\begin{array}{l}\text { Opportunity for staff nurses to consult with clinical } \\
\text { nurse specialists or expert nurse clinicians }\end{array}$} & 2.94 & 0.79 \\
\hline \multicolumn{3}{|c|}{$\begin{array}{l}\text { Good working relationships with other hospital } \\
\text { departments }\end{array}$} & 2.77 & 0.68 \\
\hline \multicolumn{3}{|c|}{ Lot of teamwork between nurses and doctors } & 2.84 & 0.74 \\
\hline \multirow{2}{*}{\multicolumn{3}{|c|}{$\begin{array}{l}\text { Doctors give high quality medical care } \\
\text { Ward manager/sister backs up nursing staff in decision } \\
\text { making, even if the conflict is with a doctor }\end{array}$}} & 2.75 & 0.69 \\
\hline & & & 3.05 & 0.90 \\
\hline \multirow{2}{*}{\multicolumn{3}{|c|}{$\begin{array}{l}\text { Collaboration between nurses and doctors } \\
\text { Ward managers/sisters consult with staff on daily }\end{array}$}} & 2.84 & 0.66 \\
\hline & & & 2.83 & 0.89 \\
\hline \multicolumn{5}{|c|}{ Registered nurses and health care assistants/auxiliaries } \\
\hline \multicolumn{3}{|c|}{ have good working relationships } & 3.32 & 0.70 \\
\hline \multicolumn{5}{|c|}{$\begin{array}{l}\text { Respondents rated the extent to which they agreed or disagreed } \\
\text { that each item was present in their current job on a } 4 \text { point scale. }\end{array}$} \\
\hline \multicolumn{5}{|c|}{ Table 3 Mean (SD) team working scores } \\
\hline & Mean & $S D$ & $n$ & \\
\hline \multicolumn{5}{|l|}{ Grade } \\
\hline D & 2.93 & 0.47 & 1667 & \\
\hline E & 2.88 & 0.45 & 2296 & \\
\hline $\mathrm{F}$ & 2.99 & 0.45 & 624 & \\
\hline \multicolumn{5}{|l|}{ Mode of working } \\
\hline Full time & 2.93 & 0.47 & 3288 & \\
\hline Part time & 2.88 & 0.46 & 1380 & \\
\hline \multicolumn{5}{|l|}{ Type of contract } \\
\hline Permanent & 2.92 & 0.46 & 4532 & \\
\hline Temporary/fixed term & 2.86 & 0.47 & 113 & \\
\hline \multicolumn{5}{|l|}{ Shift pattern } \\
\hline Day shifts only & 2.95 & 0.47 & 555 & \\
\hline Days and nights & 2.92 & 0.45 & 2756 & \\
\hline Night shifts only & 2.76 & 0.48 & 527 & \\
\hline \multicolumn{5}{|l|}{ Sex } \\
\hline Women & 2.91 & 0.46 & 4257 & \\
\hline Men & 2.88 & 0.46 & 407 & \\
\hline
\end{tabular}

Table 4 Teamwork scores by nurse variables

\begin{tabular}{|c|c|c|c|c|}
\hline & \multicolumn{3}{|c|}{ Score on teamwork scale } & \multirow[b]{2}{*}{ Total } \\
\hline & $\begin{array}{l}\text { Low } \\
(\leqslant 2.5)\end{array}$ & $\begin{array}{l}\text { Medium } \\
(2.6-3.25)\end{array}$ & $\begin{array}{l}\text { High } \\
(>3.25)\end{array}$ & \\
\hline \multicolumn{5}{|c|}{ fob satisfaction } \\
\hline \multicolumn{5}{|c|}{ On the whole, how satisfied are you with your present job? } \\
\hline Satisfied & $38 \%$ & $63 \%$ & $81 \%$ & $63 \%(n=2947)$ \\
\hline Dissatisfied & $62 \%$ & $37 \%$ & $19 \%$ & $37 \%(\mathrm{n}=1723)$ \\
\hline Total & $100 \%$ & $100 \%$ & $100 \%$ & $100 \%$ \\
\hline \multirow[t]{2}{*}{$\mathrm{n}$} & 835 & 2659 & 1176 & 4670 \\
\hline & \multicolumn{4}{|c|}{ Pearson $\chi^{2}=769, \mathrm{df}=6$, sig $=0.000$} \\
\hline \multicolumn{5}{|c|}{ Satisfaction with being a nurse } \\
\hline \multicolumn{5}{|c|}{ Independent of your present job, how satisfied are you with being a nurse? } \\
\hline Satisfied & $52 \%$ & $59 \%$ & $73 \%$ & $61 \%(n=2842)$ \\
\hline Dissatisfied & $48 \%$ & $41 \%$ & $27 \%$ & $39 \%(n=1828)$ \\
\hline Total & $100 \%$ & $100 \%$ & $100 \%$ & $100 \%$ \\
\hline \multirow[t]{2}{*}{$\mathrm{n}$} & 837 & 2658 & 1175 & 4670 \\
\hline & \multicolumn{4}{|c|}{ Pearson $\chi^{\mathrm{s}}=157, \mathrm{df}=6, \mathrm{sig}=0.000$} \\
\hline \multicolumn{5}{|c|}{ Intention to leave } \\
\hline \multicolumn{5}{|c|}{ Do you plan to leave your present nursing position? } \\
\hline Yes within the next year & $53 \%$ & $40 \%$ & $27 \%$ & $39 \%(n=1821)$ \\
\hline No plans within the next year & $47 \%$ & $60 \%$ & $73 \%$ & $61 \%(n=2823)$ \\
\hline Total & $100 \%$ & $100 \%$ & $100 \%$ & $100 \%$ \\
\hline \multirow[t]{2}{*}{$\mathrm{n}$} & 830 & 2640 & 1174 & 4644 \\
\hline & \multicolumn{4}{|c|}{ Pearson $\chi^{2}=151, \mathrm{df}=4, \mathrm{sig}=0.000$} \\
\hline \\
\hline \multicolumn{5}{|c|}{$\begin{array}{l}\text { How confident are you that you will receive adequate support when you report situations where } \\
\text { you are not able to meet professional standards of patient care? }\end{array}$} \\
\hline Very to somewhat confident & $53 \%$ & $78 \%$ & $90 \%$ & $76 \%(\mathrm{n}=3507)$ \\
\hline Not at all confident & $47 \%$ & $22 \%$ & $10 \%$ & $24 \%(n=1085)$ \\
\hline Total & $100 \%$ & $100 \%$ & $100 \%$ & $100 \%$ \\
\hline \multirow[t]{2}{*}{$\mathrm{n}$} & 826 & 2613 & 1153 & 4592 \\
\hline & \multicolumn{4}{|c|}{ Pearson $\chi^{2}=719, \mathrm{df}=6, \mathrm{sig}=0.000$} \\
\hline $\begin{array}{l}\text { Mean emotional burnout score (high } \\
\text { scores indicate greater burnout) }\end{array}$ & 28.7 & 22.8 & 18.8 & \\
\hline
\end{tabular}

opposing constructs-increased autonomy would suggest one professional group having more control while team working implies that control and power over decisions are shared.

To explore how nursing autonomy and team working relate to one another a new variable was required to summarise nurses' views of their working relationships with other members of the team. The next stage of the analysis sought to address the following four questions:

(1) Can a teamwork scale be constructed?

(2) What working environment factors are associated with greater teamwork?

(3) Are there benefits of good teamwork in terms of nurse outcomes and the perceived quality of care?

(4) How do nursing autonomy and teamwork relate to one another?

Construction of teamwork and nursing autonomy scales

The first step was to construct a team working scale. Many of the items included in the NWI appeared to cover aspects of nurses' working relationships with others. Based on their face validity, 11 items were identified that concerned relationships of staff nurses with the following groups: ward managers, doctors, nursing auxiliaries/assistants (aides), clinical nurse specialists, and other hospital departments. The items as they appeared on the questionnaire are listed in table 2. As with the other items on the NWI, respondents were asked to use a 4 point scale to indicate the extent to which they agreed or disagreed that each item was present in their current job.

After examining the correlations between the items, the mean score across the 11 component items was computed to form a single scale representing level of teamwork. The alpha reliability score for this new scale was 0.81 (which was higher than the reliability scores attained for the original three NWI derived scales).

A new nursing autonomy scale was produced since the previous version contained two items that overlapped with the team working scale. The revised nursing autonomy scale (with an alpha reliability score of 0.68 ) included the following items from the NWI:

- support for new and innovative ideas about patient care;

- nursing controls its own practice;

- freedom to make important patient care and work decisions;

- not being placed in a position of having to do things that are against my nursing judgement;

- involvement of staff nurses in the internal governance of the hospital.

Respondents were classified into three groups according to their team working scores: low $(\leqslant 2.5)$, medium (2.6-3.25), and high $(>3.25)$.

Characteristics associated with teamwork Analysis of team working by job characteristics revealed that certain groups of nurses exhibited less teamwork than others. A small but significant difference was found in the level of teamwork between full time and part time 
Table 5 Mean teamwork scores by quality of care variables

\begin{tabular}{ll}
\hline Quality of care variables & Mean score \\
\hline Quality of nursing care delivered to & \\
patients on your ward/unit & \\
Poor & 2.32 \\
Fair & 2.59 \\
Good & 2.89 \\
Excellent & 3.15 \\
Change in quality of care in hospital in last & \\
year & \\
Deteriorated & 2.73 \\
Stayed the same & 2.93 \\
Improved & 3.12 \\
Confident that patients can manage own & \\
$\quad$ care when discharged & \\
$\quad$ Not at all & 2.71 \\
Somewhat & 2.81 \\
Confident & 2.96 \\
Very confident & 3.11 \\
\hline
\end{tabular}

nurses with $27 \%$ of full time staff having high scores compared with $21 \%$ of part time staff (table 3). Working nights shifts was also associated with lower teamwork scores (2.76 v 2.95), with only $16 \%$ of staff who worked permanently on night shifts having high teamwork scores compared with $28 \%$ of those who only worked day shifts. No significant differences were found by type of contract (permanent $v$ short term), speciality of ward/unit, shift length, or job title.

What are the implications of these findings? Should employers be thinking about how to enable groups such as night staff to be more fully integrated into teams?

Teamwork by nurse outcome variables

Nurses who reported higher levels of teamwork were also significantly more likely to be satisfied with their jobs and planned to stay in them, and were likely to have lower burnout scores $(p<0.001$, table 4$)$.

Teamwork and nurse assessed quality of care Three questions in the survey addressed quality issues. Respondents were asked how they would describe the quality of nursing care

Table 6 Teamwork scores by patient care variables

\begin{tabular}{|c|c|c|c|c|}
\hline & $\begin{array}{l}\text { Low } \\
(<2.5)\end{array}$ & $\begin{array}{l}\text { Medium } \\
(2.5-3.25)\end{array}$ & $\begin{array}{l}\text { High } \\
(>3.25)\end{array}$ & Total \\
\hline \multicolumn{5}{|c|}{$\begin{array}{l}\text { In general, how would you describe the quality of nursing care delivered to patients on your } \\
\text { ward? }\end{array}$} \\
\hline Excellent & $13 \%$ & $23 \%$ & $53 \%$ & $29 \%(n=1339)$ \\
\hline Good & $49 \%$ & $63 \%$ & $44 \%$ & $55 \%(n=2591)$ \\
\hline Fair & $32 \%$ & $13 \%$ & $3 \%$ & $14 \%(n=653)$ \\
\hline Poor & $6 \%$ & $1 \%$ & 0.2 & $2 \%(n=87)$ \\
\hline Total & $100 \%$ & $100 \%$ & $100 \%$ & $100 \%$ \\
\hline \multirow[t]{2}{*}{$\mathrm{n}$} & 836 & 2656 & 1178 & 4670 \\
\hline & \multicolumn{4}{|c|}{ Pearson $\chi^{2}=812, \mathrm{df}=6, \mathrm{sig}=0.000$} \\
\hline \multicolumn{5}{|c|}{ Over the past year, would you say the quality of patient care in your hospital has: } \\
\hline Improved & $9 \%$ & $17 \%$ & $33 \%$ & $20 \%(n=904)$ \\
\hline Remained the same & $45 \%$ & $55 \%$ & $51 \%$ & $52 \%(n=2407)$ \\
\hline Deteriorated & $46 \%$ & $28 \%$ & $16 \%$ & $28 \%(n=1278)$ \\
\hline Total & $100 \%$ & $100 \%$ & $100 \%$ & $100 \%$ \\
\hline \multirow[t]{2}{*}{$\mathrm{n}$} & 824 & 2607 & 1158 & 4589 \\
\hline & \multicolumn{4}{|c|}{ Pearson $\chi^{2}=322, \mathrm{df}=4$, sig $=0.000$} \\
\hline \multicolumn{5}{|c|}{$\begin{array}{l}\text { Confident patients can manage own } \\
\text { care when discharged? }\end{array}$} \\
\hline Very to somewhat confident & $90 \%$ & $95 \%$ & $97 \%$ & $95 \%(n=4294)$ \\
\hline Not at all confident & $10 \%$ & $5 \%$ & $3 \%$ & $5 \%(n=247)$ \\
\hline Total & $100 \%$ & $100 \%$ & $100 \%$ & $100 \%$ \\
\hline \multirow[t]{2}{*}{$\mathrm{n}$} & 820 & 2580 & 1141 & 4541 \\
\hline & \multicolumn{4}{|c|}{ Pearson $\chi^{2}=247, \mathrm{df}=6, \mathrm{sig}=0.000$} \\
\hline
\end{tabular}

delivered to patients on their ward/unit (excellent, good, fair, or poor). They were also asked if the quality of care in their hospital had improved, stayed the same, or deteriorated in the past year. A third question asked nurses how confident they were that their patients were able to manage their care when discharged from hospital.

Teamwork scores varied significantly between nurses on each of these quality measures. Table 5 compares the mean team working scores on each variable and table 6 shows some of the results from cross tabulating each variable against teamwork ( $\mathrm{p}$ values all $<0.001)$.

\section{Teamwork and autonomy}

The analysis showed that teamwork and autonomy were significantly correlated with each other $(0.64, \mathrm{p}<0.01)$. Nurses with higher levels of teamwork also had higher levels of autonomy and were more involved in decision making. The relationship is depicted in the scatterplot shown in fig 1 .

For simplicity we have banded the scores for both the autonomy scale and the teamwork scale into three levels. Thus, $31 \%$ of those with a high teamwork score were also in the high autonomy group while only $1 \%$ of those with a low teamwork score had a high autonomy score. Hence, far from being opposites, the analysis would seem to suggest that working well with other members of the team is strongly associated with being able to act with professional autonomy as a nurse. While it is not possible determine the direction of this relationship, the results show the close association between the two constructs. Team working may be most effective when the staff involved have professional autonomy or, vice versa, when nurses are relating well to other members of the team they are better placed to get fully involved in decision making and act with professional autonomy. In addition to the difficulties of determining the direction of causality between nurse autonomy and teamwork, there is a more basic problem of inferring causality from correlations within a cross sectional survey; for example, the correlations could arise from a non-specific effect of positive satisfaction with one's work leading to positive reporting of all more specific components.

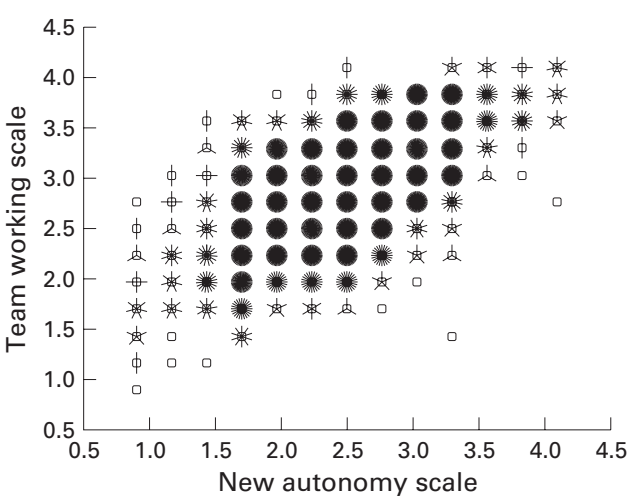

Figure 1 Scatterplot showing relationship between teamwork and autonomy. The density of the "sunflowers" represents the density of the cases. 


\section{Conclusion}

This study has shown the value of teamwork and its association with a range of positive occupational and organisational attributes such as job satisfaction, satisfaction with being a nurse, plans to remain in post, and lower levels of reported burnout. Higher reported levels of teamwork also seemed to impact on nurse assessed quality of care. Furthermore, a strong association was identified between teamwork and autonomy. It is not possible to specify whether teamwork is a pre-condition for autonomy or vice versa, but their interaction would suggest synergy rather than conflict. Organisations could therefore be encouraged to promote nurse autonomy without fearing that it might undermine teamwork. In the light of the Bristol Inquiry it is important to note that higher levels of teamwork were also associated with reports of being supported when "whistle blowing"; Stephen Bolsin, the consultant anaesthetist who blew the whistle on the surgeon's poor performance reported that he had been ostracised by the British medical establishment. ${ }^{32}$

Reciprocity and respect are the cornerstones of "social capital", defined as "features of social organisation such as trust, norms and networks that can improve the efficiency of society by facilitating coordinated action". ${ }^{33}$ There is a vast and growing literature on the subject in political science, sociology, and economics but little evidence of its application to healthcare organisations. We might speculate that organisations rich in social capital benefit from high levels of trust between workers and are less hierarchical. Clearly, further work would be required to explore the concept, its practical utility, and how it operates and flows within organisations. Such work may help to shed light on the operant mechanisms associated with organisational context and features of the relationship between teamwork and autonomy. Such an association would appear to support the call for the new professionalism first articulated in Stacey's study of the General Medical Council in the 1980s. As a lay member of the Council Stacey argued that doctors must recognise the contribution of others, including the patient, to health and modify the sacrosanct concept of autonomy and jurisdiction over allied professions. ${ }^{34}$ In essence what Stacey advocated was nothing less than the rolling back of self-regulation. Calls for more democratic forms of professionalism are not new, but the pace and direction of reform in many health systems may accelerate the trend towards multiprofessional working. Teamwork is likely to be increasingly critical to organisational performance and success in the future. Providing the evidence, we hope, contributes not only to the quality of the debate but to the debate on quality itself.

This research is part of an international effort supported by the National Institute of Nursing Research, National Institutes for Health (NR04513); the Commonwealth Fund of New York;
Agency for Healthcare Quality and Research; Alberta Heritage Foundation for Medical Research; British Columbia Health Research Foundation; the Federal Ministry of Education and Research (Germany); the Nuffield Trust, London; and the Baxter Foundation.

1 Mechanic D, Aiken LH. A cooperative agenda for medicine and nursing. N Engl F Med 1982;307:747-50.

2 Leatt P, Baker FR, Halverson PK, et al. Downsizing, reengineering and restructuring: long-term implications for healthcare organizations. Frontiers of Health Serv Manage 1997;13:27-39.

3 Aiken LH, Clarke SP, Sloane DM. Hospital restructuring: does it adversely affect care and outcomes? F Nurs Admin 2000;30:457-65.

4 Stein LI. The doctor-nurse game. Arch Gen Psychiatry 1967;16:699-703.

5 Stein LI, Watts DT, Howell T. The doctor-nurse game revisited. N Engl F Med 1990;322:546-9.

6 Casey N, Smith R. Bringing nurses and doctors closer together. BMf 1997;314:617-8.

7 Wicks D. Nurses and doctors at work: rethinking professional boundaries. Buckingham: Open University Press, 1998.

Rafferty AM. The politics of nursing knowledge. London: Rafferty AM. The
Routledge, 1996.

9 Walby S, Greenwell J, MacKay L et al. Medicine and nursing: professions in a changing health service. London: Sage, 1994

10 Strong P, Robinson J. The NHS under new management. Milton Keynes: Open University Press, 1990.

11 Traynor M. Managerialism and nursing: beyond oppression and profession. London: Routledge, 1999.

12 Irvine D, Sidnia S, McGillis Hall I. Finding value in nursing care: a framework for quality improvement and clinical education. Nurs Econ 1998;16:110-6.

13 Abbott A. The system of professions: an essay on the division of expert labour. Chicago: University of Chicago Press, 1988.

14 Allen D. The changing shape of nursing practice: the role of Aurses in the hospital division of labour. London: Routledge,
nuting 2001 .

15 Firth-Cozens J. Celebrating teamwork. Quality in Health Care 1998;7(Suppl):S3-7.

16 Firth-Cozens J. Multidisciplinary teamwork: the good, bad, and everything in between. Quality in Health Care 2001;10: 65-6.

17 Carter AJ, West MA. Sharing the burden: teamwork in health care settings. In: Firth-Cozens J, Payne J, eds. Stress in health professionals: psychological and organisational causes and interventions. Chichester: John Wiley, 1999: 191-202.

18 Borrill C, West MA, Shapiro D, et al. Teamworking and effectiveness in health care. Br f Health Care 2000;6:36471

19 Shortell SM, Zimmerman JE, Rousseau DM, et al. The performance of intensive care units: does good management make a difference? Med Care 1994;32:508-25.

20 Zimmerman JE, Rousseau DM, Duffy J, et al. Intensive care at two teaching hospitals: an organizational case study. $\mathrm{Am}$ f Crit Care 1994;3:129-38.

21 Dechairo-Marino AE, Jordan-Marsh M, Traiger G, et al. Nurse/physician collaboration: action research and the lesNurse/physician collaboration: action research
sons learned. F Nurs Admin 2001;31:223-30.

22 Zwarenstein M, Bryant W. Interventions to promote collaboration between nurses and doctors (Cochrane Review) In: The Cochrane Library. Issue 2. Oxford: Update Software, 2001.

23 Sochalski J, Aiken LA, Fagin C. Hospital restructuring in the United States, Canada and Western Europe: an outcomes research agenda. Med Care 1997;35:OS13.

24 Buchan J. Lessons from America? US magnet hospitals and their implications for UK nursing. F Adv Nurs 1994;19: 373.

25 Aiken LH, Smith HL, Lake ET. Lower medicare mortality among a set of hospitals known for good nursing care. Med Care 1994;32:771.

26 Aiken LH, Sloane DN, Lake ET, et al. Organization and outcomes of inpatient AIDS care. Med Care 1999;37:760-

27 McKee M, Aiken LH, Rafferty AM, et al. Organizationl change and quality of health care: an evolving international agenda. Quality in Health Care 1998;7:37-41.

28 Aiken L. et al. Nurse reports on hospital care in five countries. Health Aff 2001;20:43-53.

29 Aiken LH, Sochalski JA, eds. Hospital restructuring in North America and Europe: patient outcomes and workforce implications. Med Care 1997;35(Supplement).

30 Maslach C, Jackson SE. Maslach burnout inventory manual. 2nd ed. Palo Alto, California: Consulting Psychologists Press, 1986.

31 Aiken LH, Patrician P. Measuring the organizational traits of hospitals: the revised nursing work index. Nurs Res 2000; 49:146-53.

32 Key figures in the hospital drama. Guardian 19 July 2001

33 Putnam RD, Leonardi R, Nanetti RY. Making democracy work: civic traditions in modern Italy. Princeton: Princeton University Press, 1993.

34 Stacey M. Regulating British medicine. The General Medical Council. London: John Wiley, 1992

35 Hugman R. Power in the caring professions. London: Macmillan, 1991 